\title{
Pearlescent Pigments: history, properties and application in powder coatings
}

Created by: QStefano Rossi , QFrancesca Russo

Version received: 23 March 2020

check for

updates

Special effect pigments are gaining more and more attention from industries because they allow obtaining peculiar optical effects, which can be exploited in many applications, from plastics and car coatings to the cosmetic field. Among the special effect pigments, it is possible to count metal effect pigments and pearlescent pigments. The latter type shows great potentiality as these pigments are easily produced with controlled morphological characteristics, thus having unique optical properties, such as dependence of colour on the viewing angle, colour change effects and crystal-like effects. There are many types of pearlescent pigments available on the market: the most important part is represented by mica-based pigments, but also pigments based on silica or alumina flakes are becoming increasingly popular. Alumina-based pigments show the well-known advantages of micabased pigments together with the ease of incorporation in many different binders as well as peculiar optical effects. In the last decades, researchers focused their attention on the development of new pearlescent pigments; but in recent years emerged the necessity to study the behaviour of these pigments within commercial polymer binders as well. The study of the pigment-matrix system is fundamental to gain further insights on the behaviour of the single components and on their combined effects. For this reason, it is possible to assess the protection and aesthetical properties of the coatings admixed with pearlescent pigments exploiting UV exposure tests as well as salt spray exposure tests.

Pigments are substances used to modify the colour of a material, which, unlike dyes, are insoluble both in common solvents and binders. Pigments can be either organic or inorganic, though the latest type is the most used and widespread for industry applications ${ }^{[1]}$. The use of natural inorganic pigments dates to prehistoric times when natural ochre, charcoal and clays were used as colouring materials in cave paintings. The ancient civilizations of Mesopotamia and the Egyptians contributed to the development of new pigments, such as the Egyptian blue (a silicate of copper and calcium), and to the advancement of painting, enamelling and dyeing techniques. No major advancements in the development of new pigments occurred from the Greek age until the Renaissance. The pigment industry started to develop new products only in the $18^{\text {th }}$ century, but in the following centuries, the interest in pigments has grown exponentially, leading to new discoveries and technological developments. To understand the importance of the pigment market in the global industrial economy, it is sufficient to report that in 2005 the world production of inorganic pigments was in in the order of 6 million tons, for an economic turnover of 10 billions of dollars, of which at least half of it due to the production of special pigments $[\underline{2}]$. Nowadays, the industrial and academic research on pigments is mainly focused on the discovery of new pigments with better performances and on the modification of already existing pigments by substitution of toxic and non-ecological chemical substances $[\underline{3}][\underline{4}]$.

Inorganic pigments can be classified in different ways, such as by their chemical composition or technical properties, but the most useful classification can be done classifying them according to the way they interact with light. It is possible to mainly distinguish between white, coloured and black pigments and effect pigments. In the first case, the optical effects are caused by light absorption or scattering, whereas in the latter case optical effects are due to light regular reflection or light interference mechanisms ${ }^{[\underline{5}]}$. Effect pigments, also addressed as "luster pigments", show outstanding luster, high brilliance and angle-dependent optical effects, which are due to the reflection and/or interference of light on thin layers, platelets or flakes $[\underline{6}]$. Effect pigments can be used both for technical and aesthetical purposes in many industrial and end-user products, ranging from coatings (as in the automotive field), printing inks, cosmetics to plastic[]ㅡ. Effect pigments can be mainly divided into two 
sub-classes: metal effect pigments and pearlescent pigments. Metal effect pigments consist of flakeshaped metallic particles, used to give products metallic effect colour or functional properties like anticorrosion, heat resistance and conductivity ${ }^{[}[$] . The small metal platelets behave like mirrors and almost completely reflect incident light $[\underline{2}]$. Pearlescent pigments simulate the luster of natural pearls and give the materials additional colour effects, such as angular colour dependence.

\section{Pearlescent pigments}

The development of pearlescent pigments only started in the $20^{\text {th }}$ century using mercury and arsenic salts, but there were no substantial advancements until the invention of mica coated with metal oxides in 1963. From that point onward new discoveries were made in this field, as the production of aluminium-based pearlescent pigments in the 1990s[]ㅡ. Pearlescent pigments show peculiar optical effects created both by reflection on highly refractive materials and interference effects. The optical principles behind this behaviour are shown in Figure 1.

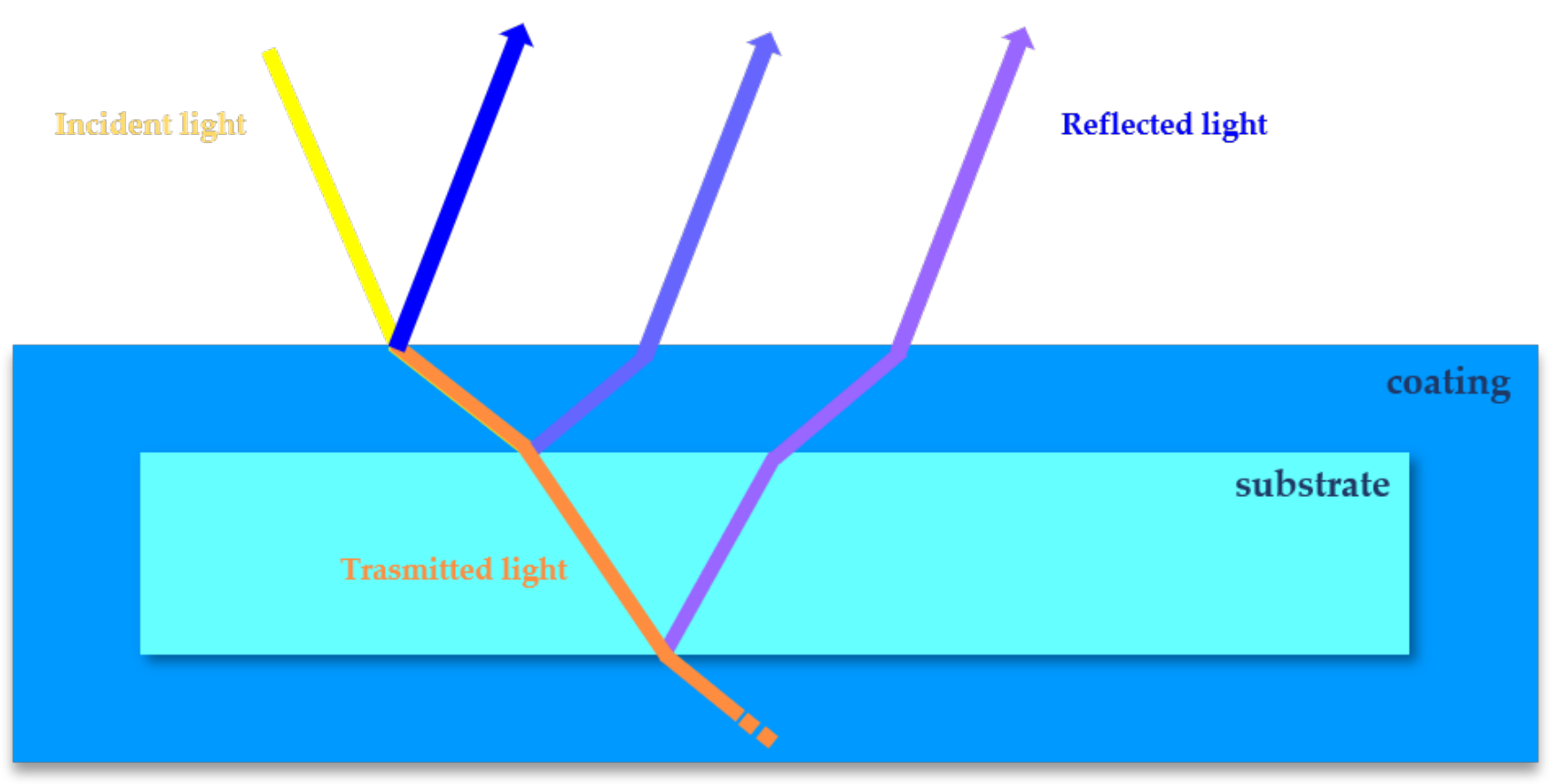

Figure 1 - Simplified diagram showing the optical behaviour of pearlescent pigments constituted by a substrate and a high refractive coating.

The simplest case to be considered is represented by a platelet-shaped particle constituted by a substrate and a layer with different refraction indexes. At each interface between materials with different refraction indices, the beam light is partially reflected and partially transmitted (i.e. refracted). Reflection and refraction mechanisms occurring at each interface cause shifts in the light wave coming off from the pigment, thus leading to interference mechanisms ${ }^{[5]}$. Pearlescent pigments have at least three layers of materials with different refractive indexes. Thus, the pearlescent effect is produced by the specular reflection of a light beam from the different interfaces present through the pigment thickness. Thin flakes (ca. $500 \mathrm{~nm}$ ) of materials with low refractive indexes, such as mica, silica, alumina or glass, are used as substrates and they are coated with high refractive materials ${ }^{[\underline{6}]}$. The thickness of the different layers can be calculated and tailored to produce the desired interference colours. When a white light beam encounters a pigment particle it is split into two different beams of complementary colours, differentiated according to the pigment thickness, which are one reflected and the other transmitted. Colours effects created by pearlescent pigments are dependent on the viewing angle because the two complementary beams respectively dominate at different viewing angles $[\underline{[5]}$. Pearlescent 
pigments are mainly divided into two different types: substrate-free pigments and layered pigments. In the first case, pigments consist of only one optically homogeneous material, whereas in the latter case pigments have a layered structure and consist of at least two optically different materials (multi-layered pigments without a substrate or pigments with a layer-substrate structure) ${ }^{[2]}$.

\section{Substrate-free pearlescent pigments}

The most common substrate-free pearlescent pigments are natural pearl essence, basic lead carbonate, bismuth oxychloride, micaceous iron oxide and $\mathrm{TiO}_{2}$ flakes. Natural pearl essence is a pigment suspension, mainly derived from fish scales or skin, constituted by high-aspect-ratio platelet-shaped particles. These particles consist of $75-97 \%$ guanine and $3-25 \%$ hypoxanthine. No industrial synthesis of this pigment is nowadays available; thus, the production of natural pearl essence is only relying on natural supply. This pigment is very expensive but shows some interesting features, such as low brittleness, high and soft luster together with very low density[9]. Considering the advantages and disadvantages of this pigment type, it is mainly used for expensive cosmetic applications. One of the first synthetic pigment that was put on the market was basic lead carbonate $\left(\mathrm{Pb}(\mathrm{OH})_{2} * 2 \mathrm{PbCO}_{3}\right)$, a lead salt crystal. This pigment can be obtained by precipitation from a lead acetate solution in the form of hexagonal crystal platelets. These platelets are less than $0.5 \mu \mathrm{m}$ thick and they have an aspect ratio of about 200. In addition to that, they have a very high refractive index (2.0) and very strong luster, but their use is limited by their high density $\left(6.4 \mathrm{~g} / \mathrm{cm}^{3}\right)$ and the presence of lead, a toxic element ${ }^{[2]}$. Bismuth oxychloride $(\mathrm{BiOCl})$ is another substrate-free pearlescent pigment type. This pigment type is produced by hydrolysis of an acid bismuth solution in the presence of chlorides. The process parameters can be adjusted to tailor the final aspect ratio of the crystals. Pigments with a low aspect ratio are usually used in cosmetics. Crystals with higher aspect ratio show an exceptional luster and they are mainly used in nail polish, buttons and jewellery. The low light stability, the high density and the poor mechanical properties these pigments have, limit their use in high-performance fields ${ }^{[\underline{5}]}$. Micaceous iron oxide consists of pure or doped iron oxide (hematite) and it is another substrate-free pearlescent pigment. It can be found in nature in the form of grey platelets or it can be synthesized by hydrothermal reactions in the form of reddish-brown platelets. The colour of this pigment can be varied using dopants such as $\mathrm{Al}_{2} \mathrm{O}_{3}, \mathrm{SiO}_{2}$ and $\mathrm{Mn}_{2} \mathrm{O}_{3}$. It is mainly used for corrosion protection coatings and only in a limited way for decorative purposes. Titanium dioxide flakes can be easily produced by breaking down a continuous film of $\mathrm{TiO}_{2}$, but it is only possible to obtain polycrystalline and porous pigments, thus having limited mechanical properties. Their use is limited as they show no optimal optical properties[2].

Substrate-free pigments show, in some cases, brittle behaviour and they often have poor mechanical properties. In addition to that, their production is limited by their chemical composition. This is the reason why new substrate-based pearlescent pigments were developed. Pigments with a substrate-layer structure have improved mechanical properties respect to substrate-free pigments, in addition to that the substrate could act as a template for the formation of the optical layer and it could become itself an optical layer if sufficiently thin. Many materials can be chosen as substrates for these pigment type, for example, mica, alumina, silica and metal flakes. The most important optical layers are constituted by titania, silica and metal oxides, iron and chromium oxides the most common ones.

\section{Layered pearlescent pigments}

The dominant class of pearlescent pigments is represented by natural mica coated with thin films of different metal oxides ${ }^{[2]}$. Mica based pigments were firstly developed in the 1970 s and got accelerated until 1990s when multilayer systems on mica were successfully realized. Natural muscovite mica is a rather inexpensive crystal and it can be easily cleaved to thinner flakes of typically $250 \mathrm{~nm}$. These advantages made mica-based pigments quickly monopolize the special effect pigment market, 
until reaching $90 \%$ of the whole market. This pigment is easily produced by the deposition of metal oxide layers on the mica surface $[\underline{2}] . \mathrm{TiO}_{2}$ or iron oxide covered mica pigments can be easily produced with a high thickness control, but sometimes they show limited optical properties[10]. Mica-based pigments with multilayers show pronounced angle dependence, but they are heavier respect to other pearlescent pigment types, thus leading to a higher pigment content required to reach a certain colour strength[11][12][13]. There are many emerging substrate-based pigments, different from the ones based on mica substrates, that show interesting optical properties. Pigments based on silica flakes $\left(\mathrm{SiO}_{2}\right)$ are easily produced in a very controlled and uniform thickness by the web-coating process ${ }^{[5]}$. The thickness of silica flakes is in the order of $400 \mathrm{~nm}$, comparable to that of mica particles, and it can be tailored be so narrow to become itself an optical layer. These pigments allow obtaining a high chromatic strength and special colour travel effects, useful for automotive applications, decorative plastics and security inks $\left[\underline{14]}\right.$. Alumina $\left(\mathbf{A l}_{2} \mathbf{O}_{3}\right)$ based pigments represent another type of emerging pearlescent pigment $[\underline{5}]$. This pigment type has got strong pearlescent effect respect to mica-based pigments mainly due to its high aspect ratio and narrow thickness distribution, as it happens for silica-based pigments. In addition to that, alumina-based pigments exhibit unique crystal-like effect (sparkle effect), mainly due to their smooth surface and chemical purity, thus being interesting for high-duty decorative purposes, such as car paints ${ }^{[2]}$. The study recently published by our group study the effect of the addition of aluminabased pigments on the durability of powder coatings. The pearlescent pigments taken under consideration were supplied by Merck S.p.A (Darmstadt, Germany). Figure 2 shows an SEM image of one of the pigments used in this study.

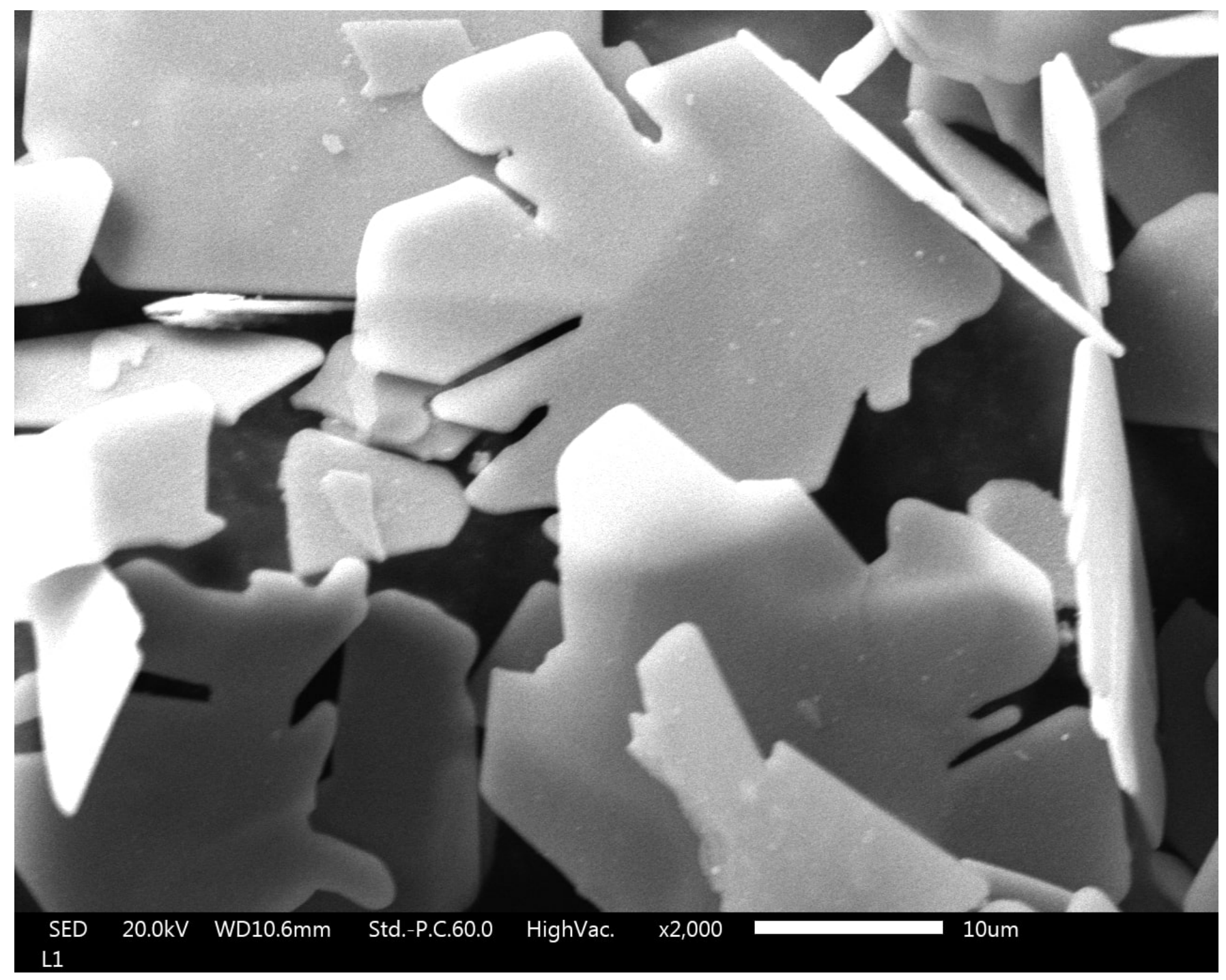

Figure 2 - SEM image of Xirallic NXT M260-30 SW pigment.

In order to be complete, it necessary to mention the presence of other substrate-based pigments such as pigments based on glass flakes and aluminium flakes. Pigments based on glass substrates play a 
minor role in the market because they are very thick and show limited optical properties, apart from special applications. Pigments base on aluminium flakes are produced via CVD processes and show an interesting angle-dependent colour changing, but the variety of colours available is limited to gold, orange and reddish metal-like colours.

\section{Pearlescent pigments in powder coatings}

Pearlescent pigments, developed in recent years, allow obtaining optical effects that cannot be reached in any other way, thus finding application in many industrial fields such as plastics, automotive, architectural application, consumer and lifestyle market, fashion, furniture and cosmetics $\underline{15}]$. Many of these pigments are produced with very simple and not energy-demanding processes, moreover, most of them are easily dispersible in many different binders and coatings. Although many advances have been made in recent years, we will certainly know new developments in this field soon. It is very interesting to see how the attention of the scientific community is now focusing not only on the development of new pigments but also on the study of their behaviour when embedded in organic coatings and subjected to weathering $[\underline{16]}$. In the last decades, the attention of materials engineers has been focused on the development of new protective coatings combining optimal functional properties as well as good aesthetical characteristics $[\underline{17]}$. Among different organic coatings available, powder coatings are arising increasing interest because they can be easily produced, and a wide range of pigments is available on the market in order to give these coatings new optical features. It is then interesting to study the behaviour of commercial powder coatings with the addition of innovative special effects pigments, assessing the coating main properties after accelerated ageing treatments, such as UV and salt spray

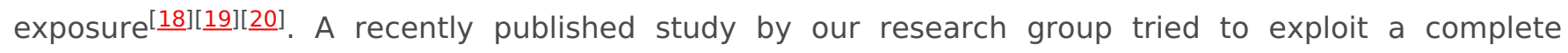
characterization of the properties of powder coatings admixed with innovative pearlescent pigments based on an alumina substrate. Changes in colour, gloss and roughness were assessed after UV-A and

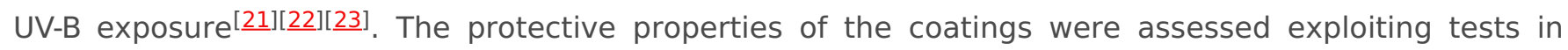
aggressive environments and evaluating the degree of coating degradation according to established standards $[\underline{24]}[\underline{25}][\underline{26]}$. The tests showed that no pigment effect can be detectable on the degradation of the coatings both by a functional and by an aesthetical point of view, which is mainly attributed to the

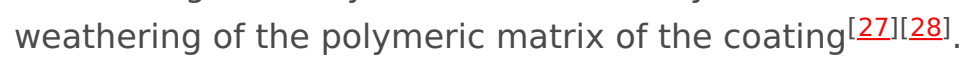

\section{References}

1. Pfaff, G.; Franz, K.; Emmert, K.; Nitta, R. Pigments, Inorganic. In Ullmann's Encyclopedia of Industrial Chemistry, 6th ed.; Wiley-VCH: Weinheim, Germany, 1998.

2. Bauxbaum, G.; Pfaff, G. Industrial inorganic pigments, 3rd ed.; Wiley-VCH: Weinheim, Germany, 2005.

3. Jansen, M.; Letschert, H.P. Inorganic yellow-red pigments without toxic metals. Nature 2000, 404, $980-982$.

4. Wendusu, T.; Masui, T.; Imanaka, N. Novel environmental-friendly inorganic red pigments based on ( $\mathrm{Bi}, \mathrm{Er}, \mathrm{Y}, \mathrm{Fe}) 2 \mathrm{O} 3$ solid solutions. J. Asian Ceram. Soc. 2014, 2, 195-198.

5. Maile, F.J.; Pfaff, G.; Reynders, P. Effect pigments - past, present and future. Prog. Org. Coat. 2005, 54, 150-163.

6. Pfaff, G. Special effect pigments: technical basics and applications; Vincentz Network GmbH \& Co KG: Hannover, Germany, 2008.

7. Pfaff, G.; Becker, M. Special effect pigments in cosmetic applications. Household and Personal Care Today 2012, 1, 12-15.

8. Faulkner, E.B.; Schwartz, R.J. High performance pigments, 2nd ed.; Wiley-VCH: Weinheim, Germany, 2009.

9. Maisch, R.; Weigand, M. Pearl Luster Pigments, Physical Principles, Properties, Applications; Verlag Moderne Industrie: Landsberg, Germany, 1992.

10. Maisch, R.; Stahlecker, O.; Kieser, M. Mica pigments in solvent free coatings systems. Prog. Org. Coat. 1996, 27, 145152.

11. Topuz, B.B.; Gündüz, G.; Mavis, B.; Çolak, Ü. The effect of tin dioxide (SnO2) on the anatase-rutile phase transformation of titania (TiO2) in mica-titania pigments and their use in paint. Dyes Pigm. 2011, 90, $123-128$.

12. Gao, Q.; Wu, X.; Fan, Y. The effect of iron ions on the anatase-rutile phase transformation of titania (TiO2) in mica 
and titania pigments. Dyes Pigm. 2012, 95, 96-101.

13. Hosseini Zori, M. Particle size and kind of mica in synthesis of nontoxic bronze and gold pearlescent pigments based on nanoencapsulated hematite. J. Ultrafine Grained Nanostruct. 2015, 48, 101-112.

14. Pfaff, G. Special effect pigments based on silica flakes. Inorg. Mater. 2003, 39, 123-126.

15. Perera, D.Y. Effect of pigmentation on organic coating characteristics. Prog. Org. Coat. 2004, 50, $247-262$.

16. Mathivanan, L.; Arof, A.K. The effect of zirconium oxide and quartz pigments on the heat and corrosion resistance properties of the silicone based coatings. Pigm. Resin Technol. 2000, 29, 10-15.

17. Ashby, M.F.; Johnson, K. Materials and design: the art and science of material selection in product design, 2nd ed.; Butterworth-Heinemann: Oxford, United Kingdom, 2009.

18. ASTM G154-16 Standard, "Standard practice for operating fluorescent ultraviolet (UV) lamp apparatus for exposure non-metallic materials", ASTM International: West Conshohocken, PA, 2016. www.astm.org

19. ASTM B117-19 Standard "Standard practice for operating salt spray (fog) apparatus", ASTM International: West Conshohocken, PA, 2019. www.astm.org

20. ASTM G85-19 Standard, "Standard practice for modified salt spray (fog) testing", ASTM International: West Conshohocken, PA, 2019. www.astm.org

21. ASTM D523-14(2018) Standard, "Standard test method for specular gloss", ASTM International: West Conshohocken, PA, 2018. www.astm.org

22. ISO 4288:1996 Standard “Geometrical Product Specification (GPS) - Surface texture: profile method - rules and procedures for the assessment of surface texture", International Organization for Standardization: Geneva, Switzerland, 2018. www.iso.org

23. ASTM E308-18 Standard, "Standard practice for computing the colors of objectives by using the CIE system", ASTM International: West Conshohocken, PA, 2018. www.astm.org

24. UNI EN ISO 4628-8(2013) Standard, "Evaluation of degradation of coatings - designation of quantity and size of defects, and intensity of uniform changes in appearance - Part 8", UNI Ente Nazionale Italiano di Unificazione: Milano, Italy, 2013

25. GSB AL 631 Standard, “International quality regulations for the coating of building components - Aluminium”, GSB International e.V.: Düsseldorf, Germany, 2017.

26. UNI EN ISO 4628-2(2016) Standard, "Evaluation of degradation of coatings - designation of quantity and size of defects, and intensity of uniform changes in appearance - Part 2", UNI Ente Nazionale Italiano di Unificazione: Milano, Italy, 2016.

27. Gheno, G.; Ganzerla, R.; Bortoluzzi, M.; Paganica, R. Accelerated weathering degradation behaviour of polyester thermosetting powder coatings. Prog. Org. Coat. 2016, 101, 90-99.

28. Maetens, D. Weathering degradation mechanism in polyester powder coatings. Prog. Org. Coat. 2007, 58, 172-179.

\section{Keywords}

pearlescent pigments; coatings; special effect pigments; weathering; powder coatings

(c) 2020 by the author(s). Distribute under a Creative Commans CC BY license 